\title{
EVALUASI STRATEGI BISNIS KEDAI KOPI NEIRA DENGAN PENDEKATAN BISNIS MODEL KANVAS
}

\author{
Muchammad Ramelan \\ Fakultas Ekonomi dan Bisnis, Universitas Airlangga \\ e-mail: muchramel@gmail.com
}

\begin{abstract}
The high competition in the coffee shop business and promising opportunities make Neira coffee shops able to adapt and develop their business. This study aimed to evaluate the business strategy of the Neira coffee shop with a canvas model business approach as well as to design a new business model through five porter analysis and SWOT analysis including identification of internal and external factors. This research used descriptive qualitative research with an independent interview method. The results of this research showed that the development of a business model in seven blocks on the canvas business model, namely the development of the customer segment was a type of professional worker or entrepreneur. The development got in the customer relationship is push notification email/ WhatsApp; in the revenue streams development is a consignment fee; in the key resources is a customer database; in the key activity is a continuous online promotion; in the key partnership is partnering with bakery shops, and in the cost structure is the cost of developing innovation.
\end{abstract}

Keywords: business model canvas; SWOT analysis; five Porter's analysis

\begin{abstract}
ABSTRAK
Tingginya persaingan dalam bisnis kedai kopi serta peluang yang menjanjikan membuat kedai Kopi Neira harus mampu beradaptasi serta mengembangkan bisnisnya. Tujuan dari penelitian ini adalah mengevaluasi strategi bisnis kedai Kopi Neira dengan pendekatan bisnis model kanvas serta merancang model bisnis yang baru melalui analisis five porter dan analisis swot meliputi identifikasi faktor internal dan faktor eksternal. Penelitian yang dilakukan merupakan penelitian kualitatif deskriptif dengan metode indepth interwiew. Hasil penelitian ini didapatkan pengembangan bisnis model pada tujuh blok pada bisnis model kanvas, yaitu pengembangan customer segment adalah jenis profesi pekerja atau wiraswasta. Pada customer relationship pengembangan yang didapat adalah push notification email/ WhatsApp; pengembangan revenue streams adalah fee konsinyasi; pengembangan key resources adalah database pelanggan; pengembangan key activity adalah promosi online yang kontinyu; pengembangan key partnership yaitu bermitra dengan toko bakery; dan pengembangan pada cost structure adalah biaya pengembangan usaha/ inovasi
\end{abstract}

Kata kunci: business model canvas; analisis SWOT; analisis Porter

\section{PENDAHULUAN}

Kebiasaan minum kopi kini tidak lagi menjadi sebuah kebutuhan serta menahan rasa kantuk, melainkan sebuah gaya hidup. Bagi sebagian masyarakat Indonesia minum kopi adalah sebuah tren, bahkan di kalangan generasi muda, minum kopi adalah sebuah moodboster, membuat mereka lebih dinamis serta inspiratif dalam melakukan aktivitas sehari-hari. Selain itu, minum kopi juga dapat bermanfaat bagi kesehatan tubuh. Dalam mengkonsumsi kopi memiliki efek menguntungkan untuk sejumlah penyakit kronis, termasuk kanker, dan kondisi kardiovaskular, metabolisme, dan neurologis (Grosso dkk., 2017).

Indonesia masuk dalam sepuluh besar negara yang memiliki tingkat penikmat kopi terbesar di dunia. Hal ini seperti yang dikemukakan oleh International Coffee Organization (ICO), World Coffee Consumption 2018/2019, konsumsi kopi di Indonesia terus meningkat hampir 4 kali lipat sejak tahun 1990, setara dengan 4,8 juta kantong $60 \mathrm{~kg}$. Negara-negara yang tergabung dalam Uni Eropa masih menjadi konsumsi terbesar di dunia dengan jumlah konsumsi 44 juta lebih kantong $60 \mathrm{~kg}$ (https://interaktif.kompas.id/baca/rajin-ngopi/).

Perkembangan bisnis kedai kopi di Indonesia 
setidaknya mengalami empat masa perkembangan. Berawal dari kedai kopi tradisional atau warung kopi yang menyediakan jenis kopi Ready to drink dengan bubuk kopi instan hingga bermunculan startup kedai kopi berkonsep Coffee To-Go. Riset TOFFIN (2020), bersama Majalah MIX MarComm SWA Media Group memaparkan adanya kenaikan jumlah kedai kopi di Indonesia pada Agustus 2019 mencapai lebih dari 2950 outlet, meningkat hampir tiga kali lipat dibandingkan pada 2016 yang hanya sekitar 1000 outlet. Peningkatan ini setidaknya membuat kondisi persaingan kedai kopi semakin sengit.

Berdasarkan hasil wawancara dengan manajemen Kopi Neira bahwa pihaknya akan terus melakukan perencanaan untuk terus tumbuh dengan menargetkan penambahan sejumlah outlet pada beberapa area di Jawa Timur, khususnya Surabaya. Jumlah Outlet yang menjadi target pada akhir tahun 2020 adalah 50 outlet, namun hingga saat ini baru berjalan 25 outlet. Jika dibandingkan dengan kompetitiornya, berdiri ditahun yang sama, kedai kopi Janji Jiwa sudah memiliki 500 outlet, kopi Kulo 300 Outlet dan Fore kopi 100 Outlet.

Adanya metamorfosis terhadap situasi dan kondisi pasar yang semakin berkembang seiring dengan perubahan teknologi serta munculnya pesaing-pesaing baru merupakan salah satu alasan perlunya evaluasi strategi bisnis yang ada agar sesuai dengan tujuan perusahaan. Manajemen Kopi Neira menyadari bawah dalam rangka usaha mengembangkan bisnis saat ini dibutuhkan langkah dan strategi bisnis yang tepat dan masif serta sesuai agar dapat menghasilkan pertumbuhan pendapatan. Pendapatan yang terus meningkat serta proyeksi bisnis yang menjanjikan merupakan pertimbangan bagi para calon investor. Menurut Berns (2016), dua kriteria yang paling dikutip untuk seorang investor adalah pengembalian yang diharapkan dan risiko yang dirasakan dari yang bersangkutan.

Persaingan bisnis pada bidang kedai kopi sangat sengit menuntut perusahaan untuk terus mengembangkan kreatifitas, ide serta keunikan yang menjadi salah satu upaya menarik pelanggan. Bisnis yang kreatif akan menghasilkan inovasiinovasi yang menjadi keunggulan dan berdaya saing dalam menghadapi kondisi saat ini dan masa depan. Langkah dalam menentukan strategi bisnis yang sesuai guna meningkatkan pendapatan salah satunya dengan melakukan inovasi pada model bisnis. Menurut Amit dan Zott (2012), inovasi model bisnis merupakan alat kompetitif yang berpotensi kuat meningkatkan keunggulan kinerja perusahaan yang berkelanjutan.

Inovasi model bisnis dapat menjadi cara yang efektif untuk memanfaatkan peluang pada saat masa transisi hingga periode gejolak ekonomi. (Giesen dkk., 2010). Menurut Magretta (2002), Model bisnis yang baik tetap penting untuk setiap kesuksesan organisasi, baik itu usaha baru atau pemain yang sudah mapan lewat sebuah nilai yang ditawarkan kepada pelanggan.

Pendekatan dalam memahami sebuah model bisnis salah satunya adalah bisnis model kanvas. Menurut Osterwalder dan Pigneur (2012), model bisnis kanvas merupakan bahasa yang sama untuk menggambarkan, memvisualisasikan, menilai, dan mengubah model bisnis. Tjitradi (2015) memaparkan bahwa bisnis model kanvas adalah model bisnis yang dapat digunakan sebagai evaluasi dan desain dari model bisnis baru yang lebih baik dan lebih modern untuk upaya berkelanjutan di masa depan. Menurut Chesbrough dan Rosenbloom (2002) bahwa sebuah perusahaan tidak dapat berjalan dengan maksimal apabila tidak didasari dengan pengkajian model bisnis yang tepat. Bisnis model kanvas adalah alat yang menjanjikan untuk mendukung memodifikasi atau menciptakan model bisnis baru dengan kecepatan yang lebih tepat (Wallin dkk., 2013).

Menurut riset yang dilakukan Blank (2013), bisnis model kanvas mampu memberikan perspektif yang lebih komprehensif dan holistik dari seluruh stakeholder perusahaan secara efektif dan efisien. Hal inilah yang menjadi dasar penelitian ini yaitu mengevaluasi strategi bisnis yang telah dijalankan kedai Kopi Neira saat ini serta mengembangkan model bisnis yang baru melalui pendekatan bisnis model kanvas. Osterwalder dan Pigneur (2012), telah mengembangkan konsep bisnis model kanvas dan menyederhanakannya menjadi Nine Building Blocks terdiri dari: Customer Segments, Value Propositions, Channels, Customer Relationship, Revenue Stream, Key Resources, Key Activity, Key Partnership dan Cost Structure

\section{METODE PENELITIAN}

Pendekatan penelitian yang digunakan dalam penelitian ini merupakan penelitian kualitatif deskriptif. Menurut Zikmund dkk (2013), tujuannya adalah untuk deskripsikan karakteristik objek, orang, kelompok, organisasi, atau lingkungan, dimana penelitian deskriptif mencoba untuk melukiskan gambaran dari situasi tertentu dengan menjawab pertanyaan siapa, apa, kapan, di mana dan bagaimana. Penentuan informan 
dilakukan dengan teknik purposive sampling, dimana pengambilan sampel dilakukan dengan sengaja berdasarkan karakteristik khusus yang sesuai dengan tujuan penelitian dengan harapan dapat menjawab masalah penelitian (Zikmund dkk., 2013). Dalam penelitian ini, sumber data primer diperoleh langsung dari internal perusahaan (manajemen Kopi Neira), serta eksternal perusahaan (Pakar/ Konsultan Kedai Kopi dan pelanggan Kopi Neira) dan data sekunder yang digunakan dalam penelitian ini bersumber dari: dokumentasi; berupa data internal perusahaan, data publikasi pemerintah dan hasil riset lembaga lain yang berkaitan, penelitian terdahulu, berita dari internet yang cukup kredibel dan dapat dipercaya. Teknik pengumpulan data yang digunakan adalah In depth Interview dan dokumentasi. Informan yang dilibatkan sebagai subjek penelitian berasal dari internal dan eksternal perusahaan dengan keterangan sebagai berikut:

a) Informan 1: DP, sebagai CEO Kopi Neira untuk mengetahui, rencana strategis hingga aktivitas-aktivitas kunci model bisnis

b) Informan 2: RS, sebagai Manajer Operasional dan SDM; untuk mengetahui strategi lingkup operasional mulai dari bahan baku hingga produk sampai ke pelanggan dan untuk mengetahui strategi kesiapan sumber daya manusia dalam mendukung kegiatan penciptaan nilai

c) Informan 3: $\mathrm{MD}$, sebagai Manajer Keuangan dan Marketing; untuk mengetahui strategi pengeluaran biaya dan aktifitas yang membutuhkan pendanaan; untuk mengetahui strategi customer relationships serta kegiatan yang mendukung revenue streams

d) Informan 4: SD sebagai Kapten Operasional; untuk mengetahui gambaran operasional outlet

e) Informan 5: FC sebagai konsultan dalam bidang Coffe Shop: untuk mengetahui gambaran bisnis kopi berdasarkan key activities, key resources, cost structure, customer relationships, channels, revenue streams

f) Informan 6-10: Pelanggan Kopi Neira; untuk mengetahui gambaran tentang value proposition, customer relationships dari sudut pandang pelanggan

Tahapan analisis data yang dilakukan dalam penelitian ini berdasarkan Osterwalder dan Pigneur (2012), yang terdiri dari: 1) Mobilize; dalam tahapan ini dilakukan identifikasi masalah dan penetapan penelitian yakni mendapatkan model bisnis kanvas untuk pengembangan Kopi Neira; 2) Understand; pada tahapan ini dilakukan identifikasi gambaran model bisnis awal Kopi Neira melalui analisis persaingan industri Porter's Five Forces yang terdiri dari; ancaman pendatang baru, daya tawar pemasok, daya tawar pelanggan, ancaman produk substitusi, serta rivalitas di antara pesaing (Porter, 2008). Model Porter's Five Forces diperlukan untuk menganalisis lingkungan persaingan yang terjadi sebagai panduan atau dasar framework perencanaan strategis untuk menciptakan keunggulan kompetitif (Hitt dkk., 2017). Sedangkan identifikasi faktor internal dan eksternal diperoleh melalui analisis SWOT untuk mengetahui kekuatan (strength), kelemahan (weakness), peluang (opportunity) dan ancaman (threat). Strategi yang tepat serta efektif akan memaksimalkan kekuatan dan peluang serta meminimalkan kelemahan dan ancaman (Pearce dan Robinson, 2008). Hasil dari analisis kemudian digunakan untuk memperdalam pemetaan blok elemen dalam mendapatkan model bisnis kanvas Kopi Neira; 3) Design; pada tahapan ini, inti penelitian dilakukan dengan menggabungkan data serta analisis untuk dipetakan dalam sembilan blok elemen model kanvas yang didapat melalui wawancara dengan pihak internal dan eksternal.

Tabel 1

Daftar Pertanyaan Wawancara

\begin{tabular}{lll}
\hline Informan & $\begin{array}{l}\text { Indikator } \\
\text { Pemahaman }\end{array}$ & \\
\hline Informan 1 & Key Activitiy & Apa sajakah aktivitas kunci yang dibutuhkan untuk model bisnis Kopi \\
& & Neira? \\
\cline { 2 - 3 } & Rivalry & Menurut Anda, siapa saja kompetitor Kopi Neira? Manakah yang menjadi \\
& Competitors & kompetitor utama? Mengapa? \\
\cline { 2 - 3 } & Customer & Siapa yang menjadi target segmen pelanggan Kopi Neira? Segmen mana \\
& Segment & yang utama? Mengapa? \\
\hline
\end{tabular}




\begin{tabular}{|c|c|c|}
\hline \multirow[t]{3}{*}{ Informan 2} & $\begin{array}{l}\text { Key } \\
\text { Resources }\end{array}$ & $\begin{array}{l}\text { Sumber daya apa yang dibutuhkan dalam memberikan value proposition } \\
\text { kepada pelanggan? Sumber daya mana yang paling penting dibutuhkan } \\
\text { dalam operasional bisnis Kopi Neira? Mengapa? }\end{array}$ \\
\hline & Channels & $\begin{array}{l}\text { Melalui saluran manakah segmen pelanggan ingin dijangkau? Apakah } \\
\text { saluran tersebut terintegrasi? Saluran mana yang paling efisien? }\end{array}$ \\
\hline & $\begin{array}{l}\text { Key } \\
\text { Partnership }\end{array}$ & $\begin{array}{l}\text { Siapa sajakah mitra yang terlibat? Manakah yang paling penting? Apa } \\
\text { yang sudah dilakukan oleh mitra tersebut? Sejauh ini bagaimana hubungan } \\
\text { Kopi Neira dengan mitra? }\end{array}$ \\
\hline \multirow[t]{4}{*}{ Informan 3} & $\begin{array}{l}\text { Customer } \\
\text { Relationships }\end{array}$ & $\begin{array}{l}\text { Bagaimana Kopi Neira mempertahankan pelanggan? Saat ini apa aja yang } \\
\text { sudah dibangun? Bagaimana tentang keluhan pelanggan? }\end{array}$ \\
\hline & $\begin{array}{l}\text { Value } \\
\text { Proposition }\end{array}$ & $\begin{array}{l}\text { Menurut Anda, Value apa yang dibutuhkan oleh pelanggan Kopi Neira? } \\
\text { sejauh ini value proposition apa yang sudah dilakukan? Bagaimana jika } \\
\text { dibandingkan dengan pesaing? }\end{array}$ \\
\hline & $\begin{array}{l}\text { Revenue } \\
\text { Stream }\end{array}$ & $\begin{array}{l}\text { Apa sajakah yang menjadi sumber pendapatan saat ini? Berapa besar } \\
\text { kontribusi masing-masing revenue? }\end{array}$ \\
\hline & $\begin{array}{l}\text { Cost } \\
\text { Structure }\end{array}$ & $\begin{array}{l}\text { Biaya apa sajakah yang dibutuhkan dalam menjalankan model bisnis Kopi } \\
\text { Neira? Berapakah kontribusi biaya tersebut dalam pendapatan? }\end{array}$ \\
\hline Informan 4 & $\begin{array}{l}\text { Key } \\
\text { Resources }\end{array}$ & Menurut Anda, adakah kendala dalam aktivitas operasional Kopi Neira? \\
\hline \multirow[t]{5}{*}{ Informan 5} & $\begin{array}{l}\text { Key Activity } \\
\& \text { Customer } \\
\text { segment }\end{array}$ & $\begin{array}{l}\text { Apa sajakah aktivitas kunci yang dibutuhkan untuk menjalankan model } \\
\text { bisnis kedai kopi? Segment mana saja yang menjadi target dalam kedai } \\
\text { kopi? }\end{array}$ \\
\hline & $\begin{array}{l}\text { Key } \\
\text { Resources }\end{array}$ & $\begin{array}{l}\text { Apa saja yang menjadi sumber utama dalam menjalankan bisnis kedai } \\
\text { kopi? }\end{array}$ \\
\hline & $\begin{array}{l}\text { Cost } \\
\text { Structure }\end{array}$ & $\begin{array}{l}\text { Biaya apa saja yang dibutuhkan untuk menjalankan model bisnis kedai } \\
\text { kopi? }\end{array}$ \\
\hline & Channels & $\begin{array}{l}\text { Saluran mana sajah yang digunakan untuk menyampaikan produk kepada } \\
\text { pelanggan? Bagaimana cara mengintegrasikan saluran tersebut? }\end{array}$ \\
\hline & $\begin{array}{l}\text { Revenue } \\
\text { streams }\end{array}$ & Apa saja yang menjadi sumber pendapatan dalam bisnis kedai kopi? \\
\hline $\begin{array}{l}\text { Informan } \\
6-10\end{array}$ & $\begin{array}{l}\text { Value } \\
\text { Proposition }\end{array}$ & $\begin{array}{l}\text { Saat ini bagaimana anda mendapatkan produk Kopi Neira? Value apa yang } \\
\text { anda dapat dari Kopi Neira? Hubungan yang seperti apa yang anda } \\
\text { harapkan sebagai pelanggan Kopi Neira? Apakah anda merekomendasikan } \\
\text { Kopi Neira kepada teman-teman anda? mengapa? }\end{array}$ \\
\hline
\end{tabular}

\section{PEMBAHASAN}

\section{Customer Segment}

Pelanggan kedai Kopi Neira termasuk dalam tipe segmented. Segmen pelanggan meliputi semua kalangan usia namun yang menjadi segmen utama kopi Neira adalah kalangan muda dengan jenis profesi mahasiswa.

\section{Value Propositons}

Secara spesifik Kopi neira menetapkan harga rendah atas pertimbangan segmen pelanggan yang mereka target. Disamping itu juga Kopi Neira mengambil bahan baku langsung dari pemasok utama tidak menggunakan pihak ketiga, hal ini yang membuat harga produksi semakin rendah. Dalam hal kualitas disini Kopi Neira menggunakan kontrol kualitas untuk setiap bahan baku yang dipesan kepada para mitra home industry, dikarenakan bahan baku yang digunakan sebagian import, terkadang Kopi Neira mengalami keterlambatan pasokan bahan baku apabila permintaan melonjak, meskipun demikian, Kopi Neira tetap berusaha memberikan pelayanan yang optimal dengan meningkatkan update stok gudang yang terintegrasi dengan sistem penjualan.

Kopi Neira berupaya semaksimal mungkin untuk memberikan image yang bagus dengan atraksi throwing dalam menyajikan produk kopi dengan topi koboy dan juga seringkali barista memberikan informasi tentang kopi selama proses pembuatannya kepada pelanggan Tabel 1 .

\section{Channels}

Saluran distribusi yang dimiliki oleh Kopi Neira menggunakan milik sendiri. Secara langsung produk didapat melalui outlet yang tersebar dan secara tidak langsung Kopi Neira bermitra dengan aplikasi ride hailing seperti Gofood dan Grabfood. 
Namun untuk penjualan online belum mampu menyaingi penjualan offline.

\section{Customer Relathionship}

Seperti halnya kedai kopi pada umumya, dalam upaya mempertahankan pelanggannya, Kopi Neira mengadakan live music untuk setiap tanggal tertentu untuk memanjakan pelanggannya. Kopi Neira juga berkolaborasi dengan para komunitas. Konsistensi dalam penggunaan media sosial untuk memberikan informasi perkembangan terbaru dan keuntungan program potongan untuk anggota member agar pelanggan tetap loyal dan setia.

\section{Revenue Streams}

Revenue Kopi Neira berasal dari penerimaan offline dan online. Penjualan offline meliputi penjualan produk secara langsung melalui outlet yang tersebar, penjualan bahan baku kepada outlet mitra. Sedangkan untuk penjualan online revenue didapat melalui aplikasi pesan antar makanan Gofood dan Grabfood. Disamping itu, Kopi Neira juga mendapatkan tambahan pendapatan dari hasil join venture kepada investor.

\section{Key Resources}

Sumber daya utama yang dimiliki oleh Kopi
Neira adalah sumber daya fisik yang meliputi outlet store, peralatan, sistem penjualan, bahan baku, pemasok. Sedangkan untuk sumber daya non fisik meliputi merek.

\section{Key Activities}

Berdasarkan kutipan wawancara dengan $\mathrm{CEO} /$ pemilik dapat diketahui bahwa aktivitas kunci Kopi Neira meliputi aktivitas produksi, service pelanggan dan menjual bahan baku ke mitra.

\section{Key Partnership}

Mitra utama dari Kopi Neira adalah home industry untuk pengolahan bahan baku powder, petani lokal untuk bahan baku kopi pilihan, platform online Gofood dan Grabfood, Spots POS untuk sistem kasir serta pembayaran non tunai seperti BCA, Gopay, Ovo, Shopeepay.

\section{Cost Structure}

Struktur biaya Kopi Neira menganut pendekatan biaya rendah atau value driven. Biaya pembelian bahan baku, biaya promosi, biaya tetap seperti gaji tenaga kerja dan biaya operasional seperti kedai kopi pada umumnya.

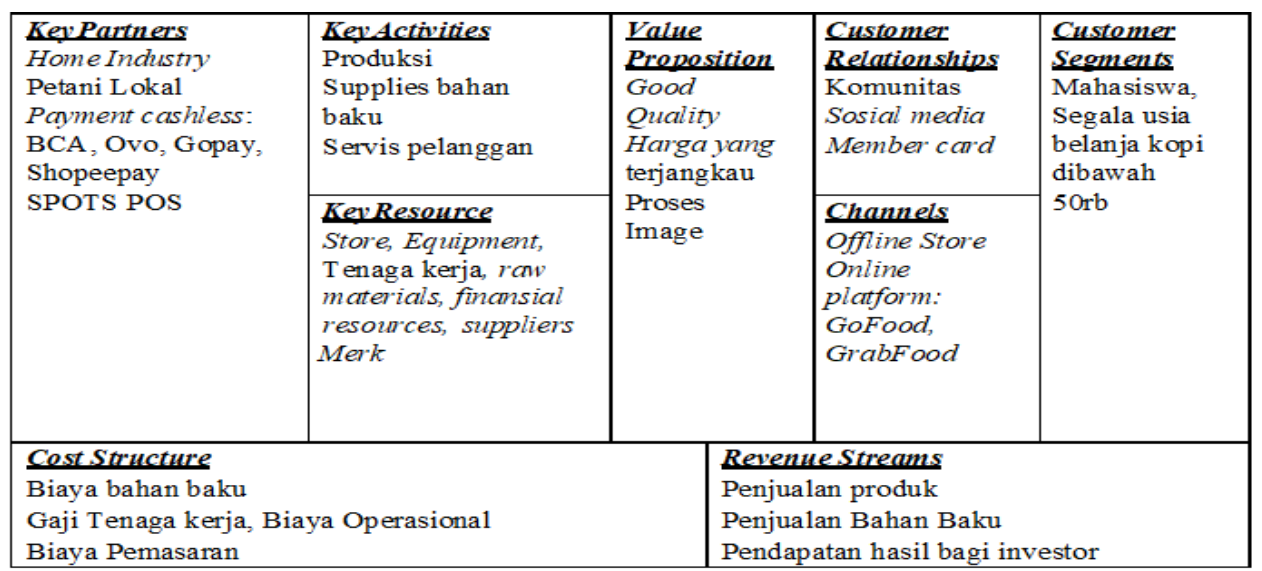

\section{Gambar 1 \\ Model Bisnis Kanvas Kedai Kopi Neira Existing Sumber: Osterwalder dan Pigneur (2012). Business Model Generation}

\section{Analisis Industri Five Forces}

Analisis persaingan industri dilakukan melalui Porter's Five Forces yang terdiri dari; ancaman pendatang baru, daya tawar pelanggan, daya tawar pemasok, ancaman produk substitusi, serta rivalitas di antara pesaing

Ancaman Pendatang Baru

Ancaman pendatang baru bagi Kopi Neira cukup tinggi. Peluang yang terdapat dalam bisnis kedai kopi atau coffee shop ini masih terbuka lebar. Kedai kopi baru bermunculan tidak membutuhkah modal yang terlalu besar, hanya dengan modal 10- 20 juta, kedai kopi sederhana dapat berjalan. Jika perusahaan- perusahaan yang sudah ada memiliki merek yang kurang bagus, maka dapat dengan mudah tergeser oleh merekmerek baru yang bisa saja lebih terkenal, dengan adanya internet atau media sosial membuat pendatang baru di bisnis ini mudah 
memperomosikan produk mereka dan juga adanya produk yang bervariasi dipasaran juga menjadi hambatan yang cukup tinggi.

\section{Daya Tawar Pemasok}

Kopi Neira memperoleh pasokan bahan baku powder dari mitra home industry dan bahan baku kopi langsung dari petani. Kopi Neira memiliki pemasok tetap dan memiliki hubungan yang baik. Pemasok tidak pernah berganti-ganti guna menjaga stok bahan baku serta kualitas tetap dipertahankan sehingga daya tawar pemasok rendah.

\section{Daya Tawar Pembeli}

Banyaknya alternatif pilihan tempat kedai kopi seperti warung kopi tradisional, tempat makan atau restoran menjadikan daya tawar pembeli sangatlah kuat. Pembeli bebas memilih tempat minum kopi sesuai keinginannya. Dalam hal ini Kopi Neira terus berusaha memenuhi kebutuhan konsumen dengan inovasi produk serta peningkatan kualitas layanan. Penetapan harga yang terjangkau dengan kualitas rasa yang mumpuni agar pelanggan tidak beralih ke lain tempat.

\section{Ancaman Produk Pengganti}

Ancaman produk pengganti atau subtisusi cukup kuat. Ancaman tersebut datang dari kedai kedai minuman yang menawarkan brand yang kuat minuman khas serta menu yang bervariasi seperti Cincau Station, Chat Time. Banyaknya pilihan konsumen terhadap produk minuman akan berdampak bagi pengurangan jumlah konsumen Kopi Neira.

\section{Persaingan antar Kompetitor}

Jumlah pemain pada industri ini sangatlah banyak dan memiliki berbagai bentuk ukuran perusahaan kecil hingga besar yang masing masing berusaha mendapatkan keuntungan dari pasar yang ada. Perang strategi harga, kualitas dan inovasi produk sering kali terjadi dalam industri kedai kopi sehingga persaingan antara pesaing yang ada sangatlah tinggi

\section{Analisis SWOT}

Faktor internal dan faktor eksternal Kopi Neira dilakukan untuk mendapatkan analisis SWOT. Faktor internal meliputi kekuatan dan kelemahan sedangkan faktor eksternal meliputi peluang dan ancaman. Faktor-faktor tersebut diperoleh melalui wawancara mendalam yaitu; Kekuatan; Lokasi yang strategis, Produk yang berkualitas, Harga terjangkau, Proses, Image.
Kelemahan; Desain kemasan; Tenaga kerja. Peluang; Pangsa pasar yang luas; Platform aplikasi pesan antar makanan online; Tren gaya hidup; Media sosial. Ancaman; Perasaingan usaha sejenis, Variasi rasa yang lebih menarik, Merek kedai kopi yang kuat, Kenaikan harga bahan baku.

Langkah-langkah kongkrit berbagai alternatif strategi didapat melalui analisis matrik SWOT. Matrik strategi yang dapat dijadikan rekomendasi ada empat macam, yaitu strategi SO, ST, WO dan WT dengan pemaparan sebagai berikut:

1. Strategi SO; Memperluas pangsa pasar; Kopi merupakan salah satu komoditas utama dengan banyak peminat mulai dari kalangan muda hingga tua, dengan berbagai status sosial sehingga menjadikan pasar kedai kopi luas. Kopi Neira dapat menggunakan kekuatan yang dimiliki seperti produk yang berkualitas, harga terjangkau, proses pelayanan serta image yang bagus untuk memanfaatkan peluang tersebut. Meningkatkan kualitas pelayanan; Upaya untuk terus meningkatkan kualitas pelayanan, Kopi Neira dapat memanfaatkan kekuatan yang dimiliki seperti barista yang terampil dalam melayani pelanggan dengan tampilan menggunakan topi koboy dan aksi proses menyajikan minuman menggunakan teknik throwing.

2. Strategi WO; Memperbaiki design kemasan; Kemasan berfungsi sebagai identitas produk, selain itu kemasan juga mampu memberikan nilai yang berbeda dan menjadi daya tarik pelanggan. Kopi Neira menggunakan kemasan produk yang tergolong cukup sederhana, hanya menggunakan gelas plastik sablon dengan opp seal plastik polos dengan desain cenderung kurang menarik. Segmen pasar sangatlah luas baik offline maupun online. Apabila produk dijual akan sulit bersaing dengan produk dengan kemasan yang lebih menarik. Menambah tim manajemen; minimnya manager fungsi sangat berpengaruh terhadap perkembangan bisnis Kopi Neira. Jabatan rangkap akan menghasilkan aktivitas yang tidak maksimal. Apabila ingin meraih pasar yang lebih luas maka Kopi Neira perlu menambah tim manajemen sehingga proses bisnis semakin mudah. Merekrut tenaga kerja yang qualified; Tenaga kerja yang dimiliki Kopi Neira saat ini kebanyakan berasal dari kalangan mahasiswa. Seringnya kendala yang terjadi dikarenakan pekerja yang absen secara tiba-tiba dengan alasan tugas kuliah yang pada akhirnya menghambat operasional kedai kopi. Oleh karena itu jika Kopi Neira menginginkan 
mengembangkan bisnisnya maka diperlukan tenaga kerja qualified dimana pekerja tersebut fokus terhadap pekerjaan.

3. Strategi ST; Mengembangkan produk/ varian baru; Kopi Neira memiliki kekuatan yaitu produk yang berkualitas dan lokasi yang strategis. Dengan memanfaatkan kekuatan maka strategi yang dapat digunakan adalah mengembangkan produk. Strategi ini bertujuan mengurangi ancaman dari kompetitor sejenis yang memiliki varian lebih menarik atau produk yang lebih inovatif. Menjaga hubungan baik pelanggan; persaingan usaha yang kompetitif serta kedai kopi dengan merek yang kuat maka diperlukan strategi bagi Kopi Neira untuk terus menjaga hubungan baik dengan pelanggan.

4. Strategi WT; Memperbaiki promosi; Strategi memperbaiki promosi secara kontinyu untuk meminimalisir ancaman kedai kopi yang memiliki merek yang kuat dan variasi rasa yang lebih menarik. Strategi ini diharapkan pelanggan lebih setia dan memunculkan jenis pelanggan baru. Mempertahankan value yang diberikan kepada pelanggan; Kopi Neira memiliki kekuatan seperti produk yang berkualitas, harga yang terjangkau, pelayanan yang baik untuk meningkatkan kepuasan pelanggan. Dengan memanfaatkan kekuatan tersebut ancaman dalam persaingan usaha dalam diminimalkan.

\section{Pengembangan Model Bisnis Kanvas \\ Customer Segment}

Berdasarkan wawancara dengan pakar dapat diketahui bahwa untuk customer segment kedai kopi olahan umumnya dari pembeli generasi $\mathrm{Z}$ dengan rentang usia 10-24 tahun dan generasi Y, 25-39 tahun. Dalam rentang usia tersebut berprofesi sebagai pelajar, mahasiswa hingga pekerja/ wiraswasta. Sedangkan untuk tingkat belanja kopi rata-rata mereka mengeluarkan kurang dari 200.000 per bulan. Jenis profesi tersebut berbeda dari customer segment yang dimiliki Kopi Neira sehingga dapat dijadikan pertimbangan dalam pengembangan bisnis model kanvas.

\section{Value Proposition}

Value kualitas rasa dan harga merupakan keunggulan sebagai daya tarik utama bagi pelanggan Kopi Neira dalam membeli produk kopi. kualitas pelayanan yang baik hingga skill barista mampu mencuri perhatian pelanggan seperti aksi throwing dengan topi koboy. Value ini tetap terus dipertahankan oleh Kopi Neira dengan harapan pelanggan semakin loyal.

\section{Channels}

Pelanggan baru pada segmen online sangatlah berpotensi. Pada kedai kopi sejenis, penjualan online mereka menyamai penjualan offline bahkan ada yang lebih besar. Saluran untuk segment online pada model bisnis Kopi Neira sudah ada namun masih belum maksimal, tingkat rata-rata penjualan online hanya $30 \%$ dari total keseluruhan penjualan sehingga dapat disarankan dengan memaksimalkan penjualan melalui aplikasi platform online dengan memberikan promo promo menarik atau paket bundle. Hal ini berdasarkan wawancara pakar bahwa generasi $\mathrm{z}$ dan $\mathrm{y}$ sangat aware dengan teknologi, mereka untuk membeli produk lewat aplikasi Gofood atau Grabfood.

\section{Customer Relationship}

Tipe hubungan yang dapat disarankan untuk Kopi Neira berdasarkan pengembangan customer segment adalah push notification email/ WhatsApp yang bersumber dari database pelanggan yang ada. Hubungan ini merupakan kategori bantuan personal dalam upaya akuisisi pelanggan, retensi pelanggan serta peningkatan penjualan. Jenis hubungan ini tidak dimiliki oleh customer relationship Kopi Neira sehingga bisa dijadikan pengembangan bisnis model kanvas.

\section{Revenue Streams}

Berdasarkan wawancara dengan pakar dapat diketahui bahwa salah satu sumber penerimaan kedai Kopi Neira adalah fee konsinyasi dengan berkolaborasi dengan usaha makanan. Jadi kedai kopi tidak hanya menyajikan minuman saja tapi juga terdapat makanan yang disupply oleh usaha makanan tersebut dengan harga dibawah pasar sehingga dapat dijadikan pengembangan bisnis model kanvas pada blok revenue streams.

\section{Key Resources}

Berdasarkan pengembangan blok customer relationships berupa push notification email/ WhatsApp, maka pengembangan key resources yang didapat adalah database pelanggan. Jenis resources ini tidak dimiliki oleh Kopi Neira sehingga dapat dijadikan pengembangan model bisnis kanvas.

\section{Key Activities}

Berdasarkan pengembangan channels untuk pelanggan online bahwa penggunaan teknologi erat dengan generasi $\mathrm{z}$ dan y khususnya pemesanan 
minuman lewat aplikasi pesan antar. Komposisi penjualan online Kopi Neira masih kecil, yakni sebesar $30 \%$ dari seluruh penjualan sehingga perlu adanya pengembangan model bisnis kanvas untuk key activities adalah promo online yang kontinyu.

\section{Key Partnership}

Berdasarkan pengembangan blok revenue streams maka pengembangan key partnership adalah bermitra dengan toko kue/ bakery. Hasil kolaborasi ini tentu saja bisa jadi pelengkap bagi kedai Kopi Neira yang hanya menyajikan produk minuman saja.

\section{Cost Structure}

Pengembangan blok cost structure pada model bisnis Kopi Neira adalah biaya pengembangan usaha/ inovasi. Hal ini berdasarkan pengembangan dari beberapa blok elemen diatas

\section{Gambar 2. Pengembangan Model Bisnis Kanvas Kedai Kopi Neira}

\begin{tabular}{|c|c|c|c|c|}
\hline \multirow[t]{2}{*}{$\begin{array}{l}\text { Key Partners } \\
\text { Home Industry } \\
\text { Petani Loka1 } \\
\text { Payment cashless: } \\
\text { BCA, Ovo, Gopay, } \\
\text { Shopeepay } \\
\text { SPOT S POS } \\
\text { Toko Bakery }\end{array}$} & $\begin{array}{l}\text { Key Activities } \\
\text { Produksi } \\
\text { Supplies bahan baku } \\
\text { Servis pelanggan } \\
\text { Promosecara } \\
\text { kontinyu }\end{array}$ & \multirow[t]{2}{*}{$\begin{array}{l}\text { Value } \\
\text { Proposition } \\
\text { Good } \\
\text { Quality } \\
\text { Harga yang } \\
\text { terjangkau } \\
\text { Proses } \\
\text { Image }\end{array}$} & $\begin{array}{l}\text { Customer } \\
\text { Relationships } \\
\text { Komunitas } \\
\text { Social media } \\
\text { Member card } \\
\text { Push notification } \\
\text { email } \\
\text { WhatsApp }\end{array}$ & $\begin{array}{l}\text { Customer } \\
\text { Segments } \\
\text { Mahasiswa, } \\
\text { Segala usia, } \\
\text { belanja kopi } \\
\text { dibawah 5Orb } \\
\text { Pekerja } \\
\text { Wiraswasta }\end{array}$ \\
\hline & $\begin{array}{l}\text { Kev Resource } \\
\text { Store, Equipment, } \\
\text { Tenaga kerja, raw } \\
\text { materials, finansial } \\
\text { resources, } \\
\text { Merk } \\
\text { Database pelanggan }\end{array}$ & & $\begin{array}{l}\text { Channels } \\
\text { Offline Store } \\
\text { Online platform: } \\
\text { GoFood, } \\
\text { GrabFood }\end{array}$ & \\
\hline \multicolumn{2}{|c|}{$\begin{array}{l}\text { CostStructure } \\
\text { Biaya bahan baku } \\
\text { Gaji Tenaga kerja, Biaya Operasional } \\
\text { Biaya Pemasaran } \\
\text { Biaya Pengembangan inovasi }\end{array}$} & \multicolumn{3}{|c|}{$\begin{array}{l}\text { Revenue Streams } \\
\text { Penjualan produk } \\
\text { Penjualan Bahan Baku } \\
\text { Pendapatan hasil bagi investor } \\
\text { Fee konsinvasi }\end{array}$} \\
\hline
\end{tabular}

Sumber: Osterwalder dan Pigneur (2012). Business Model Generation

\section{PENUTUP}

\section{Kesimpulan}

Berdasarkan hasil analisis serta pembahasan diatas dapat diambil kesimpulan yakni model bisnis Kopi Neira terdapat beberapa pengembangan pada model bisnisnya yaitu penambahan pada tujuh blok bisnis model kanvas, meliputi pengembangan blok customer segment adalah jenis profesi pekerja atau wiraswasta; blok customer relationship adalah push notification email/WhatsApp; blok revenue streams adalah fee konsinyasi; blok key resources adalah database pelanggan; blok key activity adalah promosi online yang kontinyu; blok key partnership adalah bermitra dengan toko bakery; dan pengenbangan blok cost structure adalah biaya pengembangan usaha/inovasi.

Alternatif Strategi yang didapat berdasarkan hasil analisis matrik SWOT terdiri dari empat strategi antara lain: Strategi SO; Memperluas pasar; Meningkatkan kualitas pelayanan. Strategi WO; Memperbaiki design kemasan; Menambah tim manajemen; Merekrut tenaga kerja qualified; Strategi ST; Mengembangkan produk/varian baru, menjaga hubungan baik dengan pelanggan; Strategi WT; Memperbaiki promosi; Mempertahankan value yang diberikan kepada pelanggan.

\section{Keterbatasan dan Rekomendasi Untuk Penelitian Selanjutnya}

Keterbatasan penelitian ini adalah minimnya jumlah informan wawancara mendalam yang ada pada penelitian ini yang memungkinkan kurang menggambarkan model bisnis yang ada dan rancangan pengembangan model bisnis tersebut sehingga rekomendasi untuk penelitian selanjutnya diharapkan penambahan jumlah responden melalui penyebaran kuesioner guna mendapatkan banyak informasi dalam merancang bisnis model kanvas yang baru.

\section{DAFTAR PUSTAKA}

Amit, R. and Zott, C. (2012) Creating Value through Business Model Innovation. MIT Slogan Management Review, 53, 41-49.

Blank, Steve (2013) Why the lean start-up changes everything. In: Harvard Business Review, Vol. 91 No. 5, pp. 63-72.

Chesbrough, H. and Rosenbloom, R.S. (2002) The Role of the Business Model in Capturing Value from Innovation: Evidence from Xerox Corporation's Technology Spin-Off Companies. Industrial and Corporate 
Change, 11, 529-555.

Giesen, E., Riddleberger, E., Christner, R., and Bell, R. (2010). When and How to Innovate Your Business Model. Journal Strategy \& Leadership 38(4): 17-26.

Grosso G, Godos J, Galvano F, Giovannucci EL. (2017). Coffee, Caffeine, and Health Outcomes: An Umbrella Review. Annul. Rev. Nutr. Aug, 37: 131-156.

Hitt, M. A., Ireland, R. D., dan Hoskinson, R.R. (2017). Strategic Management: Competitive \& Globalization: Concept and Cases, 12th Edition. Singapore: Cenage Learning Asia Pte Ltd.

ICO. (2019). World Coffee Consumption. International Coffee Organization (ICO). http://www.ico.org/prices/newconsumption-table.pdf

John P. Berns. (2016). Influencing Investors: an Examination of Angel Investor Perceptions of Entrepreneurial Investment opportunities. Published by ProQuest LLC (2017) pp. 122134.

Magretta, J. (2002) Why Business Models Matter. Harvard Business Review, 80, pp 86-92.

Mix Marketing \& Communication., Toffin. (2020). Brewing in Indonesia: Insights for Successful Coffee Shop Business.

Osterwalder, A. dan Pigneur, Y. (2012). Business
Model Generation, Jakarta: PT Elex Media Komputindo.

Pearce, John. A dan Robinson, Jr, Richard B. (2008). Manajemen Strategis Formulasi, Implementasi dan Pengendalian. Jakarta: Salemba Empat.

Porter. Michael E. (2008). Competitive Advantage (Keunggulan Bersaing): Menciptakan dan Mempertahankan Kinerja Unggul. Kharisma Publishing. Tangerang.

Tjitradi, Elizabeth Cindy. (2015). Evaluation and Design of Business is based on the Business Model Business Model. Journal of the University of Petra. Surabaya.

Wallin, J., Chrirumalla, K., dan Thompson, A. (2013). Developing PSS Concepts from Traditional Product Sales Situation: The Use of Business Model Canvas. Springer: Verlag Berlin Heidelberg.

Zikmund, W. G., Babin, B.J., Carr, J.C., dan Griffing, M. (2013). Business Research Methods 9th Edition. South Western Cenage Learning.

https://interaktif.kompas.id/baca/rajin-ngopi/ diakses 25 Mei 2020

https://swa.co.id/swa/trends/industri-kopiindonesia-tahun-2020-makin-kinclong diakses 26 Mei 2020 